\title{
Atypical Adenomatous Lung Hyperplasia
}

National Cancer Institute

\section{Source}

National Cancer Institute. Atypical Adenomatous Lung Hyperplasia. NCI Thesaurus. Code C5665.

A preinvasive lesion in the lung. It is characterized by the presence of a small, localized proliferation of mildly to moderately atypical type II pneumocytes and/or Clara cells lining alveolar walls and sometimes respiratory bronchioles. 